\title{
Study of Lactic Acid Level in Cerebro-Spinal Fluid And It's Prognostic Significance in Patients of Cerebral Malaria
}

\author{
Dr.Umesh Prasad ${ }^{1}$, Dr.Ashishchand ${ }^{2}$, Dr. Jag Mohan Kumar ${ }^{3}$ \\ ${ }^{I}$ Department Of Medicine/Associate Professor/R.I.M.S/Ranchi University/India \\ ${ }^{2}$ DepartmentOf Medicine/Junior Resident/R.I.M.S/Ranchi University/India \\ ${ }^{3}$ Department Of Medicine/Senior Resident/R.I.M.S/Ranchi University/India
}

\begin{abstract}
Introduction-

Cerebral malaria is defined as a diffuse cerebral encephalopathy, characterized by unarousable coma in the absence of any other attributable cause of unconsciousness (i.e. meningoencephalities, stroke, head injury, heat stroke, metabolic encephalopathies etc.) in a patient having plasmodium falciparum infection.
\end{abstract}

\section{Materials and methods}

- The present study "study of lactic acid level in cerebro-spinal fluid and its prognostic significance in patients of cerebral malaria" was carried out in the Department of Medicine, Rajendra Institute of Medical Sciences, Ranchi.

- Study Design:- Prospective observational study

- Sample Size:- 80

- Study Period:- Oct. 15 to Oct. 16

Result:-Increased CSF lactic acid was found in 100\% cases of cerebral malaria. The mean level of CSF lactic acid at presentation was found to be higher in fatal cases than in the survivors. The mean level in fatal cases was $66.62 \mathrm{mg} / \mathrm{dl}$ while in survivors, it was $39.17 \mathrm{mg} / \mathrm{dl}$.CSF lactic acid level more than 54mg/dl (double than normal) were associated with higher mortality ( $80 \%$ while $20 \%$ patients survived in this group). On the other hand, CSF lactic acid level less than $54 \mathrm{mg} / \mathrm{dl}$ were associated with low mortality (13.33\%). $\{P<0.05\}$

Conclusion:- Cerebral malaria is a medical emergency with very high mortality ,30\% mortality in this study CSF lactic acid generally rises above the normal range in almost all cases of cerebral malaria.Significantly raised CSF lactic acid (>54 mg/dl) is associated with bad prognosis and poor chances of survival, unless energetic and efficient management is done to save the patient. Significantly raised CSF lactic acid (>54mg/dl, double than the normal) level was associated adverse prognostic indicators of cerebral malaria.

Keyword:-Cerebral malaria, CSF Lactic acid, prognostic significance.

\section{Introduction}

Malaria is one of the most common \& oldest recorded parasitic infection known to mankind. It is caused by a protozoan, known as plasmodium\& transmitted by bite of infected Anopheles Mosquito.In 2010, there were an estimated 216 million (149-274 million) cases of malaria world wide, of which $91 \%$ were $P$. falciparum cases. A vast majority, about $81 \%$ were in African region followed by the South-East Asia region (13\%) and East Mediterranean (5\%). Malaria accounted for 655,000 (537,000-907,000) death of which $91 \%$ were in African region, followed by East Mediteranean(3\%) and South-East Asia region (6\%). Malaria affects mainly poor, underserved and marginalized population in remote rural areas which are characterized by inadequate control measures and limited access to health care.Malaria continues to pose a major public health threat in India, particularly due to P. falciparum which is prone to complications. In India about $27 \%$ population lives in malaria high transmission (more than 1 cases per 1000 population) areas and about 58\% in low transmission areas (0-1 case per 1000 population) areas. About $92 \%$ of malaria cases and $97 \%$ of deaths due to malaria is reported from North-eastern states, chhattisgarh, Jharkhand, MP, Orissa, AP, Maharashtra, Gujarat, Rajasthan, WB and Karnataka. Malaria in man is caused by six distinct species of genus Plasmodium-

1)P.vivax,

2) P.falciparum,3) P.malariae,4) two morphologically identical sympatric species of P.ovale. 5)P.knowlesi Plasmodium falciparum causes the most severe illness.

In person with P. falciparum malaria specially with poor immunity, the irregularly or regularly spaced paroxysm are associated with marked prostration and after 7 to 10 days, a rapid deterioration follows in the patient's condition associated with shock and other complications and even death if untreated such malaria(caused by P.falciparum) is known as severe falciparum malaria.Death from P. vivax, P. ovale or P. 
malaria infection is very rare. The commonly associated complications of severe falciparum malaria are- coma or cerebral malaria, severe anaemia, renal failure, pulmonary edema, or ARDS, hypoglycaemia, circulatory collapse or shock, spontaneous bleeding, repeated generalized convulsions, lactic acidosis.

Cerebral malaria manifests as diffuse symmetric encephalopathy, focal neurological sign are unusual. Although some passive resistance to head flexion may be detected, sign of meningeal irritation are lacking. Muscle tone may be either increased or decreased. The tendon reflexes are variable, and the planter reflexes may be flexor or extensor. Flexor or extensor posturing may be seen. Approximately 15\%of patients have retinal haemorrhages. Convulsions, usually generalized and often repeated, occur in up to $50 \%$ of children with cerebral malaria. More covert seizure activity is also common particularly among children, and may manifest as repetitive tonic-clonic eye movements or even hypersalivation.

Hypoxia \& ischemia of brain has been described as the major possible cause, which can occur due to interference to the micro-circulatory flow to the brain. Besides coma may be compounded by hypoglycaemia, lactic acidosis \& shock if present. Intravascular sequestration of the parasitsed red cells due to cyto-adherence \& rosette formation leads to interference in the micro-circulatory blood flow to the brain, obstruction mainly taking place in the cerebral capillaries \& post capillary venules. This interference lead to cerebral anoxia and ischemia causing altered sensorium, obtundation\& coma. The anoxia \& ischemia of brain leads to cerebral anaerobic glycolysis, resulting in to formation of lactic acid in excess amounts, which are reflected in to CNS as raised lactic acid level.

\section{Material And Method}

The present study was carried out in the Department of Medicine, Rajendra Institute of Medical Sciences, Ranchi.

Inclusion criteria:

1) Primary pool- patients hospitalized with complain of fever with clinical diagnosis of malaria.

2) Secondary pool- the cases from primary pool with definite diagnosis of cases of P. falciparum malaria along with features suggestive of cerebral malaria.

\section{Exclusion criteria:}

1) Pre-existing neurological disorders

2) Patients with pre-existing convulsive disorder

80 cases of different age and sex of fever with coma without any other attributable cause of unconsciousness, the presence of positive blood smear or positive rapid test (kit test) for plasmodium falciparum were selected with the clinical diagnosis of cerebral malaria.

\section{The following investigations have been done in cases under study:}

1) Blood for TC \& DC of WBCs, $\mathrm{Hb} \%$ estimation.

2) Peripheral blood smear both thick and thin for the presence of pla.falciparum.

3) Rapid diagnostic kit test for Pla.falciparum.

4) RBS

5) Examination of CSF for protein, sugar, cells, and lactic acid.

The study of lactic acid level in CSF was done with the help of semiautolyzer test.

\section{Statistical Analysis}

Chi-square test was used to find the significance of frequency distribution of study parameters between group CSF lactic acid more than $54 \mathrm{mg} / \mathrm{dl}$ and less than $54 \mathrm{mg} / \mathrm{dl}$. Student $\mathrm{t}$ test was used to find the significance of mean values of study parameters between both the groups. Microsoft Excel and Word were used to prepare the tables and graphs.

\section{Result}

The total no of cases studied $(n=80) .50(62.5 \%)$ were male while $30(37.5 \%)$ were female.The age of cases under varied 17 years to 55 years. Mean age of patients under study 34.41. The maximum incidence of the disease was observed in 21 - 40years age - group (61.5\%). Number of case was from rural area $63(78.75 \%)$ and from urban area17 $(21.25 \%) .57(71.25 \%)$ of cases under study were from tribal community and $23(28.75 \%)$ are non-tribal.(table 1)

The age group less than 20 yrs the observed mortality was $16.67 \%$ while in the age group 21-40 years the observed mortality was $34.61 \%$.In the age group of 41-60 years mortality was found to be $25 \%$.

History of fever with rigor,(100\%), headache (100\%), unconsciousness (100\%) \& absent neck stiffness (100\%) were present in all cases of cerebral malaria at the time of presentation. Convulsion was present in $30 \%$ cases. 
Vomiting was present in $12.5 \%$ cases while dehydration was present in $35 \%$ of cases, corneal reflux was absent in $27.5 \%$.Jaundice was present in $12.5 \%$ of cases. Hepatomegaly was found in $27 \%$ cases while splenomegaly was present in $37.5 \%$. Both hepato-splenomegaly were found together in $25 \%$ cases, Acute renal failure was present in $7.5 \%$ cases.Hence a history of fever with rigor, headache, altersensorium, absent neck rigidity, anaemia was the most common presentation.Dehydration, convulsion, hepatomegaly, splenomegaly, acute renal failure , jaundice and decerebrate rigidity were sometimes present.

Cerebral malaria patients, presenting with random blood sugar (RBS) less than 70mg/dl were 18 in number with the percentage of fatality was $55.56 \%$. While 62 patients were found RBS more than $70 \mathrm{mg} / \mathrm{dl}, 77.42 \%$ cases survived and only $22.58 \%$ cases were fatal $(\mathrm{P}<0.05)$. Severe anemia $(\mathrm{Hb}<=7 \mathrm{gm} / \mathrm{dl})$ was found in 20 cases with mortality of $70 \%$ while only $30 \%$ patients survived with severe anemia. Lesser degree of anemia $(\mathrm{Hb}>7 \mathrm{gm} / \mathrm{dl})$ was found in 60 cases with mortality of $83 \%$ of patients $(\mathrm{P}<0.05)$. In the fatal cases of cerebral malaria, the mean CSF lactic acid level was found $66.26 \mathrm{mg} / \mathrm{dl}$ with standard deviation of 16.91 while in the survivors; the mean CSF lactic acid was $39.17 \mathrm{mg} / \mathrm{dl}$ with standard deviation of 7.66 .

The actual difference between the mean is 27.45(66.62-39.17).Unpaired t test (student $t$ test) is applied and $\mathrm{p}$ valve is found significant $(\mathrm{P}<0.05)$. (Table 2) CSF lactic acid levels more than $54 \mathrm{mg} / \mathrm{dl}$ (double than normal) were associated with a mortality of $80 \%$ while $20 \%$ patient survived in this group. On the other hand, CSF lactic acid level less than $54 \mathrm{mg} / \mathrm{dl}$ were associated with a mortality of $13.33 \%$, while $86.67 \%$ patients survived in the group.Chi square test is applied- The observed difference between the mortality (or survivor) figures of the two groups is significant $(\mathrm{p}<0.05)$. So lactic acid $>54 \mathrm{mg} / \mathrm{dl}$ was associated with very high mortality. CSF lactic acid $<54 \mathrm{mg} / \mathrm{dl}$ was associated with better survivor.(Table 3 )

Table 1-Age distribution of cases under study

\begin{tabular}{|l|l|l|l|l|l|l|}
\hline $\begin{array}{l}\text { Age group } \\
\text { (Years) }\end{array}$ & $\begin{array}{l}\text { No. of cases } \\
(\mathrm{n}=80)\end{array}$ & $\begin{array}{l}\% \text { of cases in } \\
\text { given age group }\end{array}$ & $\begin{array}{l}\text { No. of male } \\
\text { cases }\end{array}$ & $\begin{array}{l}\% \text { of male } \\
\text { patient }\end{array}$ & $\begin{array}{l}\text { No. of female } \\
\text { cases }\end{array}$ & $\begin{array}{l}\% \text { of female } \\
\text { patient }\end{array}$ \\
\hline$<20$ yrs & 12 & $15 \%$ & 6 & $50 \%$ & 6 & $50 \%$ \\
\hline $21-40$ yrs & 52 & $65 \%$ & 32 & $61.5 \%$ & 20 & $38.5 \%$ \\
\hline $41-60$ yrs & 16 & $20 \%$ & 12 & $75 \%$ & 4 & 25 \\
\hline Total cases & 80 & 100 & 50 & $62.5 \%$ & 30 & $37.5 \%$ \\
\hline
\end{tabular}

Table 2- Showing mean level of CSF lactic acid level and standard deviation in fatal and survived cases of cerebral malaria.

\begin{tabular}{|l|l|l|l|}
\hline & $\begin{array}{l}\text { NO. OF } \\
\text { CASES }\end{array}$ & $\begin{array}{l}\text { MEAN CSF LACTATE } \\
(\mathrm{Mg} / \mathrm{Dl})\end{array}$ & STANDARD DEVIATION \\
\hline $\begin{array}{l}\text { FATAL CASES OF CEREBRAL } \\
\text { MALARIA }\end{array}$ & 24 & 66.62 & 16.91 \\
\hline $\begin{array}{l}\text { SURVIVORS OF CERE BRAL } \\
\text { MALARIA }\end{array}$ & 56 & 39.17 & 7.66 \\
\hline
\end{tabular}

Table 3showing elation ship between CSF lactic acid level and prognosis in patients of cerebral malaria

\begin{tabular}{|l|l|l|l|l|l|}
\hline & $\mathrm{n}$ & $\begin{array}{l}\text { fatal } \\
\text { case }\end{array}$ & $\begin{array}{l}\text { survivors } \\
\text { cases }\end{array}$ & $\%$ mortality & $\%$ survival \\
\hline $\begin{array}{l}\text { Patients of cerebral malaria with CSF } \\
\text { lactic acidlevel }>54 \mathrm{mg} / \mathrm{dl} \text { malaria }\end{array}$ & 20 & 16 & 4 & 80 & 20 \\
\hline $\begin{array}{l}\text { Patients of cerebral malaria with CSF } \\
\text { lactic acidlevel<54mg/dl malaria }\end{array}$ & 60 & 8 & 52 & 13.33 & 86.67 \\
\hline
\end{tabular}

Figure 1 - Showing Age \& Sex Distribution Of Patients

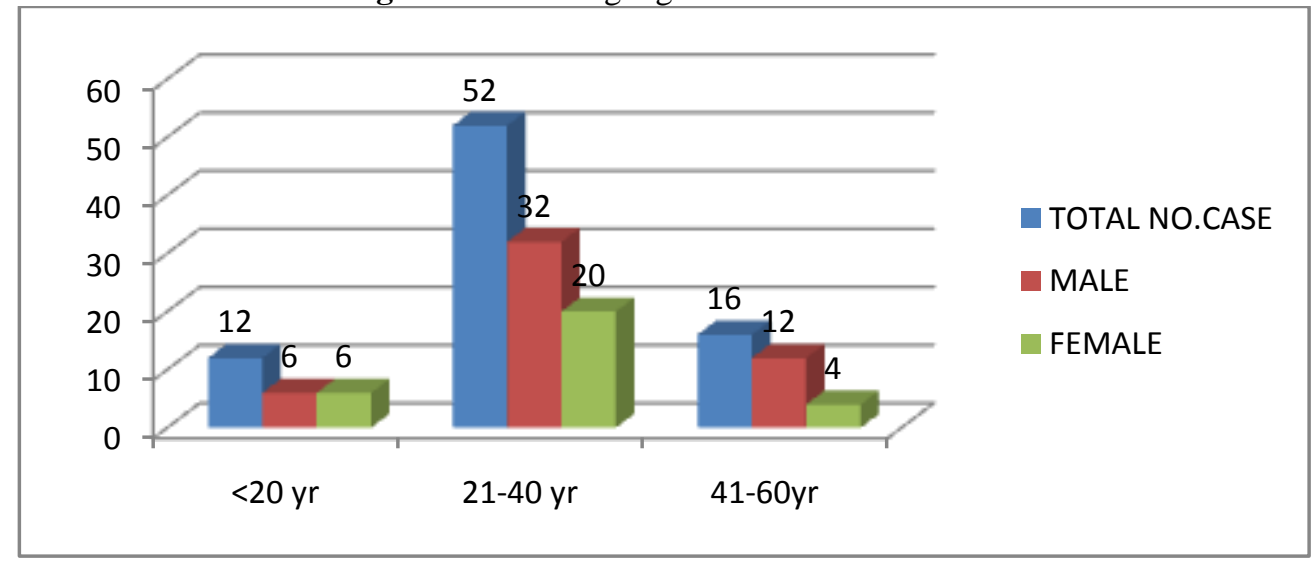

Figure 2- showing means CSF lactic acid level in fatal \& surviving cases of cerebral malaria 


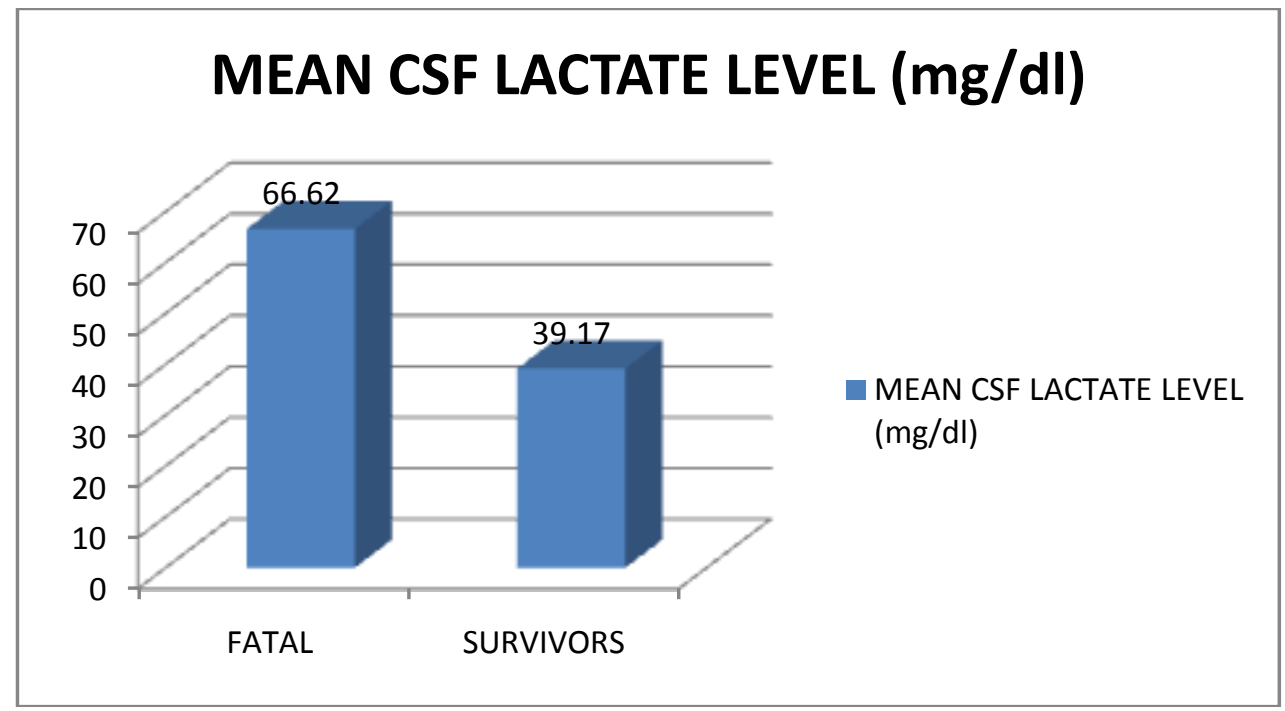

Figure 3showing relationship between two group of CSF lactic acid \& Prognosis

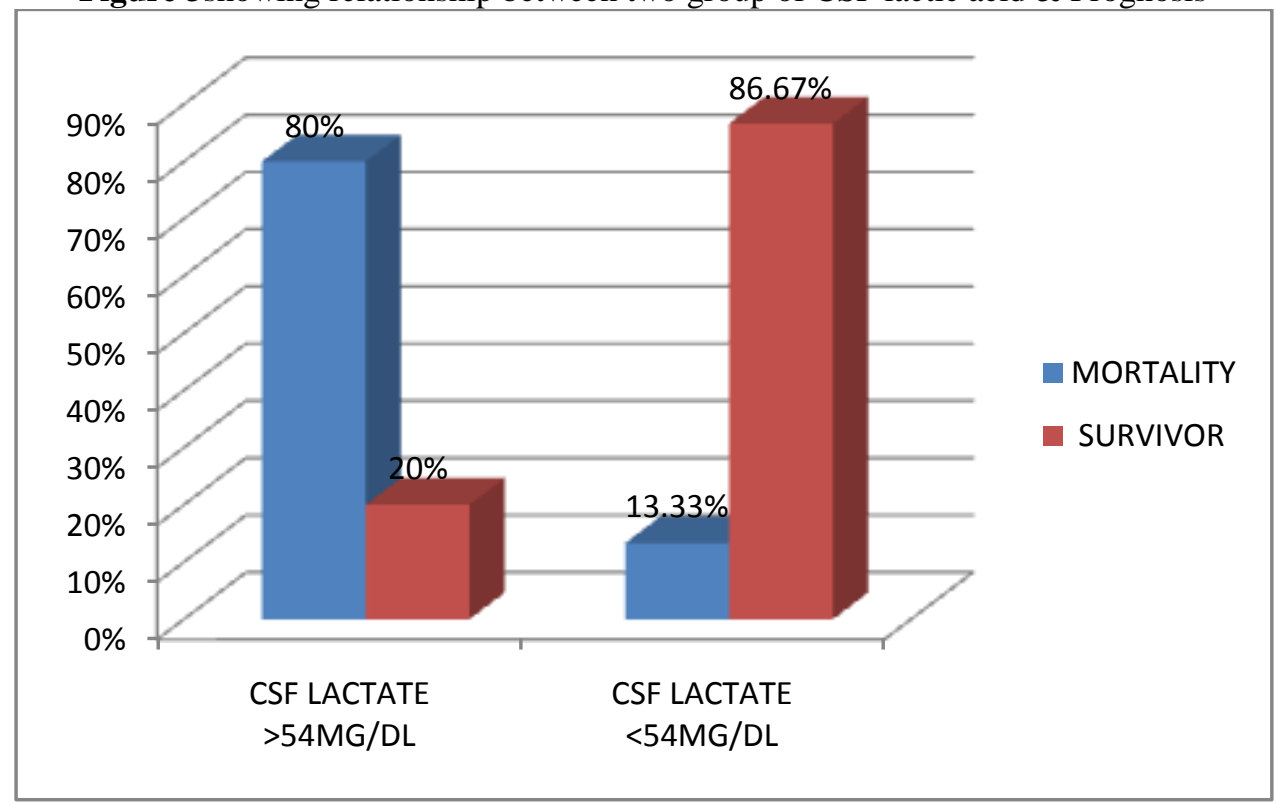

\section{Discussion}

In a study carried out by white and warrel et.al.in $(1985)^{5}$ forty five patients had been studied. Out of this $64 \%$ were male and $36 \%$ were female with the mean age of patient being 23 years. In another study carried out by Turner ,Morrision et.al.(1994) ${ }^{16}$ the age varied from 19-67 years and the mean age of occurrence was 35 year. In present study mean age of patient is 34 year.62.5\% were male and $37.5 \%$ were female which is compatible with previous study.In a study carried out by Phillips and Gilles $(1988)^{17}$ they found mortality rate ranging from $20-25 \%$. In present study mortality is $30 \%$. The clinical sign which were associated with mortality in this study were deep unconsciousness with Glasgow coma scale score 7 or less (69\% mortality, $n=26,18$ died, 4 survived ), absent corneal reflex ( $82 \%$ mortality, $n=22,18$ died 4 survived), severe anaemia with haemoglobin equal to $7 \mathrm{gm} / \mathrm{dl}$ or less (70\%mortality, $\mathrm{n}=20,14$ died ,6 survived ), occurrence of convulsion (58.33\% mortality, $\mathrm{n}=24,14$ died, 10 survived). In a study carried out by Molyneux, Taylor et.al.(1988) ${ }^{18}$ on the clinical features and prognosis indicators in cerebral malaria, 131 patients were studied. Mortality was $15 \%$ .The clinical sign which were associated with adverse prognosis were profound coma (65\% mortality), absent corneal reflex (55\% adverse prognosis) and convulsions (38\% mortality). These finding are in consistence with but on the lower side than the finding of the present study. History of high fever with rigor, headache, anaemia, altered sensorium or unconsciousness with absent neck stiffness was the most comman (100\%) mode of presentation. Convulsions were found in $30 \%$ of cases. These finding are in consistence with other studies. 
CSF lactic acid level was increased in all 80 cases. In the fatal cases, the CSF lactic acid ranged from $41.44 \mathrm{mg} / \mathrm{dl}$ to $93.36 \mathrm{mg} / \mathrm{dl}$. If CSF lactic acid was very high (>54 mg/dl), patients generally had high mortality $\left(\mathrm{n}=20,16\right.$ died, 4 survived ). In the study carried out by White N.J. Warrel D. A. Et.al $(1985)^{5}$, CSF lactic acid was found to be raised in 44 patient's ofcerebral malaria out of 45 cases with a percentage of $98 \%$. Another study carried out by Molyneux ,Taylor et. Al. (1989) ${ }^{18}$, CSF Lactic acid was raised in 93 patients out of 131 cases $(71 \%)$. These results are in consistence with the results obtained in this study but higher side.

Mean level of CSF lactic acid in fatal cases was $66.62 \mathrm{mg} / \mathrm{dl}$,(S.D.= 16.91,S.E.=3.6) while in survivors , it was $39.17 \mathrm{mg} / \mathrm{dl}($ S.D.=7.66,S.E.=3.6) and P value <0.05. So the mean level of CF lactic acid at presentation was found to be higher in fatal cases than in the survivors. These results are significant and are in consistence with the wok of White N.J. Warrel D. A. Et.al $(1985)^{5}$ they found CSF lactic acid in fatal cases mean -standard deviation $=9.0+-5.3 \mathrm{~m} \mathrm{~mol} / \mathrm{L}$ vs CSF lactic acid in survivors $(3.4+-1.1 \mathrm{mmol} / \mathrm{L}), \mathrm{P}=0.0002$ and Taylor, wirima, Molyneux (1989) ${ }^{18}$ [CSF lactic acid in fatal cases $=5.3+-3.3 \mathrm{mmol} / \mathrm{L}$ vs CSF lactic acid in survivors $=3.68+-1.6 \mathrm{mmol} / \mathrm{L}](1 \mathrm{mmol}$ lactic acid $=9 \mathrm{mg} / \mathrm{dl})$.

In our study it was found that if CSF lactic acid level more than $54 \mathrm{mg} / \mathrm{dl}$ than mortality was $80 \%$ ( $\mathrm{n}=20,16$ died, 4 survived), while if it was less than $54 \mathrm{mg} / \mathrm{dl}$ than mortality was $13.33 \%$ ( $\mathrm{n}=60,8$ died, 52 survived). In study carried out by White N.J. Warrel DA $(1985)^{5}$, all patients with CSF lactate level above $6 \mathrm{mmol} / \mathrm{L}(=54 \mathrm{mg} / \mathrm{dl})$ had died $(100 \%$ mortality $)$. Hence these finding are in consistence with the finding obtained in the present study.

In our study patients, presenting with random blood sugar (RBS) less than $70 \mathrm{mg} / \mathrm{dl}$ were 18 in number with the percentage of fatality was 55.56\%. While 62 patients were found RBS more than $70 \mathrm{mg} / \mathrm{dl}, 77.42 \%$ cases survived and only $22.58 \%$ cases were fatal $(\mathrm{P}<0.05)$.In a study carried by Marsh, Foster, et. al. $(1995)^{20}$ found hypoglycaemia to be a risk factor for adverse prognosis in patients of cerebral malaria(relativerisk3.3,95\%c.i.=1.6to6.7)in addition to other factor. Waller, Krishna , crawley ey.al,(1986) ${ }^{21}$, while studying the clinical feature and outcome of sever malaria in Gambian children, found hypoglycaemia to be independent indicator of poor prognosis beside other factor .

\section{Conclusion}

On the basis of above results obtained in the present study, the following conclusions have been drawn:-

Cerebral malaria is a medical emergency with very high mortality ranging from $25-50 \%$ (30\% mortality in this study).It predominantly affects non-immune and partially immune persons.CSF lactic acid generally rises above the normal range in almost all cases of cerebral malaria.Significantly raised CSF lactic acid (>54 mg/dl) is associated with bad prognosis and poor chances of survival, unless energetic and efficient management is done to save the patient. Significantly raised CSF lactic acid $(>54 \mathrm{mg} / \mathrm{dl}$, double than the normal) level was also associated with the presence of other established adverse prognostic indicators of cerebral malaria like absent corneal reflex, decerebrate posturing, GCS score $<7$, severe anemia etc.

\section{References}

[1]. Harrison'sprinciple of internal medicine $19^{\text {th }}$ edition page $-1368-1384$

[2]. Park's text book of preventive \& social medicine $23^{\text {rd }}$ edition 2015 page no- $255-269$

[3]. API 2015 conference medicine update - severe and complicated malaria.

[4]. The role of cerebral oedema in the pathogenesis of cerebral malariaL.A. SanniPages 137-142

[5]. White N.J., Warrell and Looreesuwanet.al.The lancet -volume 325, issue 8432(1985)page no 776-8

[6]. Oxford journal of medicineM. E. MOLYNEUX, T. E. TAYLOR, J. J. WIRIMA, A. BORGSTEINJ( 1989)

[7]. Kanaani ,J.and Ginsburg ,H.(1991).Transport of lactate in plasmodium falciparum infected human erythrocytes .J.Cell.Physiol. 149, 469-476

[8]. Jalloh,I.,Helmy,A.,Shannon,R.J.Gallagher ,C.N.,Menono,D.K.Carpenter,K.L., et al (2013).Lactate uptake by the injured human brain :evidence from anaterivenous gradient and cerebral microdialysis study .J.Neurotrauma 30,2013-2037

[9]. Warrell D.A ,White N.J.Looareesuwan S et.al (1988)- cerebral anaerobic glycolysis \& reduced cerebral oxygen transport in human cerebral malaria - 534-538

[10]. Lando ,Djiogue and Djoumessi (1995)- The prognostic valve of CSF lactate determination in cerebral malaria in Cameroonian child -Bull. Soc.Pathol.Exot (1995) page 152-155

[11]. kochar D BanshiLalKuniawat, Karan S and Other sever and complicated malaria in Bikaner ,Western India.The south East Asian Journal Trop Med Public Heaith1997 ;28 259-267

[12]. Lewallen S, Harding SP, Ajewole J, et al. A review of the spectrum of clinical ocular fundus findings in P falciparum malaria in African children with a proposed classification and grading system. Trans $\mathrm{R}$ Soc Trop Med Hyg 1999;93: 619-22. 
[13]. Oxford journal of medicineM. E. MOLYNEUX, T. E. TAYLOR, J. J. WIRIMA, A. BORGSTEINJ( 1989)

[14]. The Journal of Infectious Diseases 2002;185:650-6Infectious Diseases Society of America. Isabelle M. Medana,TranTinhHien, Nicholas P.NguyenHoanPhu, Nicholas J. White, and Nicholas H. Hun.

[15]. Cecil's text book of medicine $25^{\text {th }}$ edition .

[16]. Turnar GDH, morrison. H,et.al.(1994) -an immunological study of the pathology of fatal malaria American Journal of pathology(1994)145:1057-1069

[17]. Philips R.E., Gilles H.M.- malaria medicine International journal (1988);01:2220-25

[18]. Molyneux M.E., TaylorT.E.,Wirima J.J.,\&Borgstein A (1989) clinical feature \& prognostic indicators in pediatric cerebral malaria : A study of 131 comatose Malawian children -Qr J.Med.,Newseris 71,No.265,(May1989)P:441-59

[19]. March K., Foster D.et.al.(1995)-Indicators of life threatening malaria in African children N.England.J.Medicine (1995)May 25 ;332(21);1399-1404

[20]. Waller. D,Krishna. S, Crawley. J.et.al(1995)-clinical feature \& outcome of severe malaria in Gambian children : clinical infect. Disease (1995)sep :21(3):557-87 